\title{
Applicability of Sediment Transport Capacity Models for Nonsteady State Erosion from Steep Slopes
}

\author{
Gokmen Tayfur ${ }^{1}$
}

\begin{abstract}
The physics-based sediment transport equations are derived from the assumption that the sediment transport rate can be determined by a dominant variable such as flow discharge, flow velocity, slope, shear stress, stream power, and unit stream power. In modeling of sheet erosion/sediment transport, many models that determine the transport capacity by one of these dominant variables have been developed. The developed models mostly simulate steady-state sheet erosion. Few models that are based on the shear-stress approach attempt to simulate nonsteady state sheet erosion. This study qualitatively investigates the applicability of the transport capacity models that are based on one of the commonly employed dominant variables-unit stream power, stream power, and shear stress-to simulate nonsteady state sediment loads from steep slopes under different rainfall intensities. The test of the calibrated models with observed data sets shows that the unit stream power model gives better simulation of sediment loads from mild slopes. The stream power and the shear stress models, on the other hand, simulate sediment loads from steep slopes more satisfactorily. The exponent $\left(k_{i}\right)$ in the sediment transport capacity formula is found to be 1.2, 1.9, and 1.6 for the stream power model, the shear stress model, and the unit stream power model, respectively.
\end{abstract}

DOI: 10.1061/(ASCE)1084-0699(2002)7:3(252)

CE Database keywords: Sediment transport; Slopes; Erosion; Shear stress.

\section{Introduction}

Erosion/sediment transport by sheet flow has been experimentally studied. Kilinc and Richardson (1973) carried out intensive rainfall simulations over different slopes from 5.7 to $40 \%$ to study the mechanics of soil erosion from overland flows generated by simulated rainfall. Mosley (1972) examined the effect of slope and catchment size and slope on rill morphology and water and sediment transport discharge from interrill areas and rills. In his experimental study, Mosley (1972) had eight different slopes, ranging from 3 to $12 \%$. Moss and Walker (1978), Moss (1979), and Moss et al. (1980, 1982) carried out rainfall simulations over slopes ranging from 0.1 to $4.2 \%$ to measure the total sediment concentration of sheet flow and to study the formation of rills. Loch and Donnollan (1983a,b) and Loch (1984) measured sediment discharge under simulated rainfall over $4 \%$ tilted slopes after steady-state runoff had been achieved. Govindaraju et al. (1992) carried out rainfall simulations over a steep slope of decomposed granite to assess the performance of cut/fill slopes prone to erosion.

Mathematical models have been developed to study sediment transport by sheet flow too. Some researchers tried to formulate predictive equations based on watershed parameters (Flaxman 1972). Some derived regression equations based on their experimental data (Kilinc and Richardson 1973; Leaf 1974; Megahan

\footnotetext{
${ }^{1}$ Associate Professor, Dept. of Civil Engineering, Izmir Institute of Technology, Gulbahce, Urla 35437, Izmir, Turkey.

Note. Discussion open until October 1, 2002. Separate discussions must be submitted for individual papers. To extend the closing date by one month, a written request must be filed with the ASCE Managing Editor. The manuscript for this paper was submitted for review and possible publication on February 2, 2001; approved on August 16, 2001. This paper is part of the Journal of Hydrologic Engineering, Vol. 7, No. 3, May 1, 2002. (CASCE, ISSN 1084-0699/2002/3-252-259/\$8.00+\$.50 per page.
}

1974) and some developed black-box type models (Guldal and Muftuoglu 2001). A more physics based modeling approach that provides the spatial and/or temporal distribution of unknown quantities has been attempted by Meyer and Wischmeier (1969), Rowlinson and Martin (1971), Foster and Meyer (1972), Smith (1976), Li (1979), Foster (1982), Woolhiser et al. (1990), and Govindaraju and Kavvas (1991). Most of these physics-based models have a continuity equation for the conservation of the sediment mass and another equation that relates sediment load to the flow transport capacity.

Most physics-based sediment transport equations were derived from the assumption that the sediment transport capacity could be determined by a dominant variable such as flow discharge, flow velocity, slope, shear stress, stream power, and unit stream power. The sediment transport capacity is expressed by the basic form

$$
T_{c}=\eta_{i}\left(D-D_{c}\right)^{k i}
$$

where $T_{c}=$ transport capacity $(M / L / T) ; \eta_{i}$ and $k_{i}=$ parameters related to flow and sediment conditions; $D=$ dominant variable; and $D_{c}=$ critical condition of dominant variable at incipient motion.

In physics-based sheet erosion modeling research the shear stress approach has found a wide application in simulating steadystate sediment transport (Foster and Meyer 1972; McWorter et al. 1979; Foster 1982) and nonsteady state sediment transport (Li 1979; Woolhiser et al. 1990; Govindaraju and Kavvas 1991). The unit stream power approach has also been employed by many researchers to simulate equilibrium sediment loads by sheet flow (Smith 1976; Alonso et al. 1981; Wilson et al. 1982, 1984; Moore and Burch 1986). On the other hand, Rose et al. (1983a,b) employed the stream power approach to simulate sediment loads at steady state.

With the exception of studies by Govindaraju and Kavvas (1991), Woolhiser et al. (1990), and Li (1979), most of the other physics-based mathematical modeling work involved studying 
sediment transport under steady-state conditions from slopes of $0.1-12 \%$. Each study investigated the performance of whichever transport capacity model was employed to study the sheet erosion under steady-state conditions. However, to the knowledge of the writer, there is no study that qualitatively investigated the applicability of all of the commonly employed sediment transport models in estimating sediment loads from steep slopes under nonsteady state conditions.

The objective of this study is to investigate the applicability of the most commonly employed sediment transport capacity models to simulate nonsteady state sediment loads from steep slopes under different rainfall intensities. Although Yang (1996) concludes that the sediment transport rate or concentration should be related to the rate of the energy dissipation approach, on which the unit stream power and the stream power models are based, the shear stress approach has been successfully employed by many researchers, as stated above. Therefore, in this study the performance of the unit stream power, the stream power, and the shear stress approaches is extensively investigated to simulate nonsteady state sediment transport under different rainfall intensities from steep slopes.

\section{Mathematical Development}

There are two parts in modeling rain-induced surface erosionflow dynamics and erosion dynamics. By solving the flow dynamics, one obtains the flow depth and velocity fields on the land surface and the flow discharge from the land surface. The computed flow depth and velocity fields are, in turn, used for the erosion dynamics to predict the sediment concentration field on the land surface and the sediment discharge from the land surface. This approach explicitly assumes that the sediment concentrations in the overland flow regime are sufficiently small so that the suspended sediment does not affect the flow dynamics. Under this assumption, one can simulate these two processes independently. This assumption has been commonly employed by many researchers (Foster and Meyer 1972; Li 1979; Govindaraju and Kavvas 1991).

\section{Flow Dynamics}

Kinematic wave approximation (KWA) is used for modeling nonsteady state flow dynamics in one dimension. Since this study focuses on sediment transport from steep slopes, KWA in one dimension is a fairly good approximation to the full Saint-Venant equations. The KWA equation in one dimension is stated as

$$
\frac{\partial h}{\partial t}+\frac{\partial}{\partial x}\left(K h^{5 / 3}\right)=(r-i)
$$

where

$$
K=\frac{\sqrt{S}}{n}
$$

and where $h=$ overland flow depth $(L) ; r=$ rainfall intensity $(L / T) ; i=$ infiltration rate $(L / T) ; S=$ bed slope; and $n=$ Manning's roughness coefficient $\left(L^{1 / 3} / T\right)$.

\section{Erosion Dynamics}

The physics-based one-dimensional nonsteady state erosion/ sediment transport equation can be expressed as (Li 1979; Woolhiser et al. 1990)

$$
\frac{\partial(h c)}{\partial t}+\frac{\partial}{\partial x}(q c)=\frac{1}{\rho_{s}}\left(D_{r d}+D_{f d}\right)
$$

where

$$
q=K h^{5 / 3}
$$

and where $c=$ sediment concentration by volume $\left(L^{3} / L^{3}\right)$; $\rho_{s}=$ sediment particle density $\left(M / L^{3}\right) ; q=$ unit flow discharge $\left(L^{2} / T\right) ; D_{r d}=$ soil detachment rate by raindrops $\left(M / L^{2} / T\right)$; and $D_{f d}=$ soil detachment/deposition rate by sheet flow $\left(M / L^{2} / T\right)$.

\section{Soil Detachment by Raindrops}

Soil detachment is a function of the erosivity of rainfall and the erodibility of the soil particles. The erosivity is directly related to the energy produced by raindrop impact and is generally formulated as a power function of rainfall intensity, size of the droplet, cover condition, and terminal velocity of the drop (Meyer and Wischmeier 1969). On a bare soil surface, detachment by raindrops can be expressed as ( $\mathrm{Li} 1979)$

$$
D_{r d}=\alpha r^{\beta}\left(1-\frac{z_{w}}{z_{m}}\right)
$$

where $\alpha=$ soil detachability coefficient, which depends on the soil characteristics $\left(M / L^{2} / L\right)$. Soil properties known to affect the erodibility include primary particle size distribution, organic matter content, soil structure, content of iron and aluminum oxides, electrochemical bonds, initial moisture content, and aging (Partheniades 1972). Sharma et al. (1993) obtained the range of $0.0006-0.0086 \mathrm{~kg} / \mathrm{m}^{2} / \mathrm{mm}$ for $\alpha$ for easily detachable soils and $0.00012-0.0017 \mathrm{~kg} / \mathrm{m}^{2} / \mathrm{mm}$ for less detachable soils. Note that in Eq. (6) $r$ is in millimeters per hour, $\alpha$ is in kilograms per meter squared per millimeter, and $D_{r d}$ is in kilograms per meter squared per hour. The range for $\alpha$ obtained by Sharma et al. (1993) is in agreement with Foster (1982).

The parameter $\beta$ is an exponent whose range is 1.0-2.0. From experimental studies, it is shown that $\beta=2.0$ (Meyer 1971; Foster 1982). Sharma et al. (1993) showed that the value of $\beta$ is in the range of 1.09-1.44. Foster et al. (1977) used a value of $\beta$ of 1.0. Tayfur (2001) showed that the change in the value of $\beta$ in between 1.0 and 1.8 does not affect the sediment discharge significantly. In the present study, the value of $\beta$ is taken as 1.0.

Parameter $z_{w}$ is the flow depth plus the loose soil depth $(L)$, and $z_{m}$ is the maximum penetration depth of raindrop splash $(L)$. Eq. (6) is valid when $z_{w}<z_{m}$; otherwise, there is no detachment by the raindrops. According to Mutchler and Young (1975), $z_{m}$ can be equal to three times the median raindrop size and the median raindrop size can be expressed as a power function of rainfall intensity. According to Li (1979)

$$
z_{m}=3\left(2.23 r^{0.182}\right)
$$

Note that in Eq. (7), $r$ is in millimeters per hour and $z_{m}$ is computed in millimeters.

Eq. (6) expresses the detachment by raindrop impact as a power function of rainfall intensity, flow depth, and loose soil depth. As the sum of the flow depth and loose soil depth increases, the penetration depth decreases and consequently the detachment by raindrops decreases.

\section{Soil Detachment/Deposition by Sheet Flow}

The soil detachment/deposition rate is proportional to the difference between the sediment transport capacity and the sediment load in the flow. This implies that the flow has the maximum eroding capacity when it is free of suspended sediment. When the 
sediment load is greater than the transporting capacity, deposition occurs. The soil detachment/deposition by sheet flow can be expressed as (Foster 1982; Govindaraju and Kavvas 1991)

$$
D_{f d}=\varphi\left(T_{c}-q_{s}\right)
$$

where

$$
q_{s}=\rho_{s} c q
$$

where $q_{s}=$ unit sediment discharge $(M / L / T)$. If the transport capacity exceeds the existing unit sediment discharge $\left(T_{c}>q_{s}\right)$, the flow will detach particles; otherwise, it will deposit the particles. Parameter $\varphi$ is the transfer rate coefficient $(1 / L)$, which may vary over a wide range, depending upon the soil type. Foster (1982) gives the range $\varphi=3-33 \mathrm{~m}^{-1}$ for sand. In the present study, during detachment $\left(T_{c}>q_{s}\right), \varphi$ is taken as $24 \mathrm{~m}^{-1}$. During deposition $\left(T_{c}<q_{s}\right), \varphi$ is estimated as a function of particle terminal fall velocity $\left(V_{f}\right)$ and the unit flow discharge $(q)$ as (Foster 1982)

$$
\varphi=\left(0.5 V_{f}\right) / q
$$

The particle terminal fall velocity may be estimated from the particle density and size, assuming that the particles have drag characteristics and terminal fall velocities similar to those of spheres. Yang (1996) expresses the particle terminal fall velocity
$\left(V_{f}\right)$ as a function of the particle diameter and the particle Reynolds number. The particle Reynolds number can be expressed as (Woolhiser et al. 1990)

$$
\mathscr{R}_{p n}=\frac{V_{f} d}{v}
$$

where $V_{f}=$ particle terminal fall velocity $(L / T) ; \mathscr{R}_{p n}=$ particle Reynolds number; $d=$ particle diameter $(L)$; and $v=$ kinematic viscosity of water $\left(L^{2} / T\right)$.

When the particle Reynolds number $\left(\mathscr{R}_{p n}\right)$ is less than 2.0 , the terminal fall velocity of a particle is expressed as (Yang 1996)

$$
V_{f}= \begin{cases}\frac{1}{18} \frac{\left(\gamma_{s}-\gamma\right)}{\gamma} \frac{g d^{2}}{v} ; & d \leqslant 0.1 \mathrm{~mm} \\ F\left[\frac{g d\left(\gamma_{s}-\gamma\right)}{\gamma}\right]^{0.5} ; & 0.1 \mathrm{~mm}<d \leqslant 2.0 \mathrm{~mm} \\ 3.32 \sqrt{d} ; & d>2.0 \mathrm{~mm}\end{cases}
$$

where $g=$ gravitational acceleration $\left(L / T^{2}\right) ; \gamma_{s}=$ specific weight of sediment $\left(M / L^{2} / T^{2}\right)$; and $\gamma=$ specific weight of water $\left(M / L^{2} / T^{2}\right)$; and

$$
F=\left\{\begin{array}{l}
{\left[\frac{2}{3}+\frac{36 v^{2} \gamma}{g d^{3}\left(\gamma_{s}-\gamma\right)}\right]^{0.5}-\left[\frac{36 v^{2} \gamma}{g d^{3}\left(\gamma_{s}-\gamma\right)}\right]^{0.5} ; \quad 0.1 \mathrm{~mm}<d \leqslant 1.0 \mathrm{~mm}} \\
0.79
\end{array}\right.
$$

Note that in Eq. (12), $V_{f}$ is in meters per second and $d$ is in meters.

When the particle Reynolds number is greater than 2.0, the terminal fall velocity is determined experimentally. Yang (1996) gives a figure summarizing the fall velocity values depending on the sieve diameter and the shape factor. For most natural sands, the shape factor is 0.7 . Rouse (1938) gives $V_{f}=0.024 \mathrm{~m} / \mathrm{s}$ for $d$ $=0.2 \mathrm{~mm}$. In the present study, for $\mathscr{B}_{p n}>2.0$, the terminal fall velocity is assumed to be $0.024 \mathrm{~m} / \mathrm{s}$.

Transport Capacity Models. Sheet flow transport capacity is a function of several factors that include runoff rate, flow velocity, slope steepness of the surface, transportability of detached soil particles, and the effect of raindrop impact. The basic relationship that does not take into account the effect of raindrop impact on the transport capacity might be a typical sediment transport equation form of Eq. (1). Depending upon the chosen model for the sediment transport capacity of sheet flow, the dominant variable can be shear stress, stream power, and the unit stream power. In the following sections, a brief description of each approach is given.

Shear Stress Approach. The transport capacity model that is based on the dominant variable shear stress can be expressed as (Foster 1982; Govindaraju and Kavvas 1991; Yang 1996)

$$
T_{c}=\eta_{\tau}\left(\tau-\tau_{c}\right)^{k_{\tau}}
$$

where

$$
\tau=\gamma h S
$$

and where $\tau=$ shear stress, which is the tractive force developed by the sheet flow to overcome the critical shear stress $\left(M / L / T^{2}\right)$; and $\eta_{i}=$ soil erodibility coefficient, which is a function of particle diameter and density. While its value may vary over a wide range, Foster (1982) suggests the value of 0.6 for $\eta_{i}$. Parameter $k_{i}=$ exponent whose value varies between 1 and 2.5 . Foster (1982) suggests the value of 1.5 for $k_{i}$. Parameter $\tau_{c}=$ critical shear stress $\left(M / L / T^{2}\right)$, which is a function of the particle diameter and specific weight of the sediment and water. Li (1979) expresses $\tau_{c}$ as

$$
\tau_{c}=\delta_{s}\left(\gamma_{s}-\gamma\right) d
$$

where $\delta_{s}=\mathrm{a}$ constant dependent on flow conditions. Gessler (1965) shows that $\delta_{s}$ should be 0.047 for most flow conditions. If rilling develops on the overland flow surface, the value of $\delta_{s}$ should be lower (Li 1979). Parameter $\tau_{c}$ represents the resistance of the soil against erosion. The critical shear stress is very small for cohesionless soils, and it is often neglected (Foster 1982).

Stream Power Approach. Bagnold (1960) was the first person who introduced the stream power concept and defined it as the power per unit area of stream bed (shear stress times flow velocity, $\tau V)$. The transport capacity model that is based on the dominant variable stream power can be expressed as (Yang 1996)

$$
T_{c}=\eta_{\tau v}\left(\tau V-\tau_{c} V_{c}\right)^{k_{\tau v}}
$$

where $V=$ flow velocity $(L / T)$; and $V_{c}=$ critical flow velocity at incipient sediment motion $(L / T)$. In Eq. (17), $\tau V=$ stream power and $\tau_{c} V_{c}=$ critical stream power at incipient sediment motion. $V$ is computed from the flow dynamics part of the model as

$$
V=K h^{2 / 3}
$$


Yang (1996) expresses the critical flow velocity as being dependent upon the shear velocity Reynolds number. The shear velocity Reynolds number is expressed as

$$
\mathscr{R}^{*}=\frac{u_{*} d}{v}
$$

where $u_{*}=$ shear velocity $(L / T)$ and is defined as (Yang 1996)

$$
u_{*}=\sqrt{g h S}
$$

The critical flow velocity at incipient sediment motion is expressed as (Yang 1996)

$$
V_{c}= \begin{cases}\frac{2.5 V_{f}}{\log \left(\mathscr{R}^{*}\right)-0.06}+0.66 V_{f} ; & 1.2<\mathscr{R}^{*}<70 \\ 2.05 V_{f} ; & \mathscr{R}^{*}>70\end{cases}
$$

Unit Stream Power Concept. Yang (1972) was the first person who introduced the unit stream power concept. Yang (1973) and Yang and Song (1979) defined unit stream power as the time rate of potential energy dissipation per unit weight of water (flow velocity times energy gradient, which is approximated by the slope of the soil surface or channel bed, $V S$ ). The transport capacity model that is based on the dominant variable unit stream power can be expressed as (Yang 1996)

$$
T_{c}=\eta_{\boldsymbol{v} s}\left(V S-V_{c} S_{c}\right)^{k_{\boldsymbol{v} s}}
$$

where $S=$ energy slope, which is assumed to be equal to the bed slope; and $S_{c}=$ critical slope at incipient sediment motion. In Eq. (22), $V S=$ unit stream power; and $V_{c} S_{c}=$ critical unit stream power at incipient sediment motion. By utilizing Meyer-Peter and Muller's (1948) bed load equation, the slope at incipient motion $\left(S_{c}\right)$ can be obtained as

$$
S_{c}=\frac{0.058 d n^{1.5}}{h d_{90}^{0.25}}
$$

where $d_{90}=$ bed material size, where $90 \%$ is finer $(L)$. Note that in Eq. (23), $h, d$, and $d_{90}$ are in meters.

\section{Solution Procedure}

Eqs. (2) and (4) were solved numerically by using the implicit centered finite difference method. The Newton-Raphson iterative technique was used to solve the set of nonlinear equations resulting from the implicit procedure. As upstream boundary conditions, zero flow depth and zero sediment concentration were used. As downstream boundary conditions, zero depth gradient and zero sediment concentration gradient were employed. Since rainfall starts on a dry surface, there is initially no flow and erosion on the hillslope surface. Under the specified initial and boundary conditions, the numerical solutions of Eqs. (2) and (4) are executed simultaneously for each time step. Every time step, Eq. (2) is first solved to obtain flow depths, flow velocities, and unit flow discharges. Then Eq. (4) is solved to compute sediment concentrations and unit sediment discharges. Every time step $(j)$, the loose soil depth $\left(l_{d}\right)$, which is required by Eq. (6), is also computed. The loose soil depth at the $(j+1)$ time step is computed as

$$
l_{d}(j+1)=l_{d}(j)-\left[D_{r d}(j)+D_{f d}(j)\right] \frac{\Delta t}{\rho_{s}}
$$

The details of the numerical scheme can be obtained from Tayfur (1990).

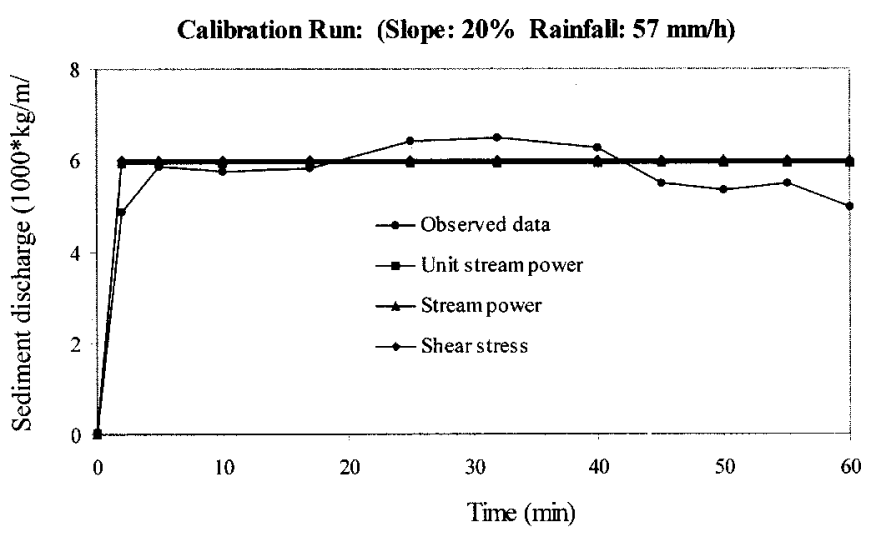

Fig. 1. Simulation of observed data; calibration run $(S=20 \%, r$ $=57 \mathrm{~mm} / \mathrm{h}$ )

\section{Analysis of Results}

The applicability of the unit stream power, stream power, and shear stress approaches is investigated to simulate nonsteady state sediment transport under different rainfall intensities from steep slopes. For this purpose, the experimental data of Kilinc and Richardson (1973) were chosen.

Kilinc and Richardson (1973) performed experimental studies by using a $1.21 \mathrm{~m}$ high $\times 1.52 \mathrm{~m}$ wide $\times 4.58 \mathrm{~m}$ long flume with an adjustable slope. Commercial sprinklers on $3 \mathrm{~m}$ risers, placed $3 \mathrm{~m}$ apart along the sides of the flume, simulated rainfall. The flume was filled with compacted sandy soil (90\% sand and $10 \%$ silt and clay), which was leveled and smoothed before each run. The soil had a nonuniform size distribution with $d_{50}=0.35 \mathrm{~mm}$ (the median diameter of the sediment recorded for $50 \%$ of the samples having a diameter finer than this size) and $d_{90}=1.3 \mathrm{~mm}$. The compacted sandy soil had a bulk density of $1,500 \mathrm{~kg} / \mathrm{m}^{3}$ and a porosity of 0.43 . The major controlled variables were rainfall intensity and soil surface slope. Infiltration and erodibility of the surface were constant. Six bare slopes (5.7, 10, 15, 20, 30, and $40 \%$ ) were tested with four different rainfall intensities (32, 57, 93 , and $117 \mathrm{~mm} / \mathrm{h}$ ). On average, the constant infiltration rate for each run was about $5.3 \mathrm{~mm} / \mathrm{h}$. Runoff was recorded continuously and sampled for sediment concentration every 5-10 min during each hour-long run. The details of the experimental setups and experiments can be obtained from Kilinc and Richardson (1973).

One of the data sets of Kilinc and Richardson (1973) was used for the calibration of the model parameters. Fig. 1 shows the calibration run for the case of $57 \mathrm{~mm} / \mathrm{h}$ rainfall intensity and $20 \%$ slope. The calibrated values of the model parameters that resulted in the best fit for the observed experimental data (Fig. 1) are as follows:

- Manning's roughness coefficient $(n): 0.012\left(\mathrm{~m}^{1 / 3} / \mathrm{s}\right)$,

- Soil detachability coefficient $(\alpha): 0.0012\left(\mathrm{~kg} / \mathrm{m}^{2} / \mathrm{mm}\right)$,

- Soil erodibility coefficient $\left(\eta_{\tau}=\eta_{\tau v}=\eta_{v s}\right): 0.10$,

- (Unit stream power) exponent $\left(k_{\boldsymbol{v} s}\right): 1.56$,

- (Stream power) exponent $\left(k_{\tau v}\right): 1.18$, and

- (Shear stress) exponent $\left(k_{\tau}\right): 1.92$.

These values are within the ranges suggested in the literature (Foster and Meyer 1972; Woolhiser 1974; Li 1979; Foster 1982; Sharma et al. 1993). Note that the calibrated parameter values are the same for each model. The only difference is that the values of the exponents $\left(k_{\boldsymbol{v} s}, k_{\tau \boldsymbol{v}}, k_{\tau}\right)$ are different for each model.

The calibrated values of the model parameters were then employed in the simulation of different data sets. Figs. 2(a-e) show 

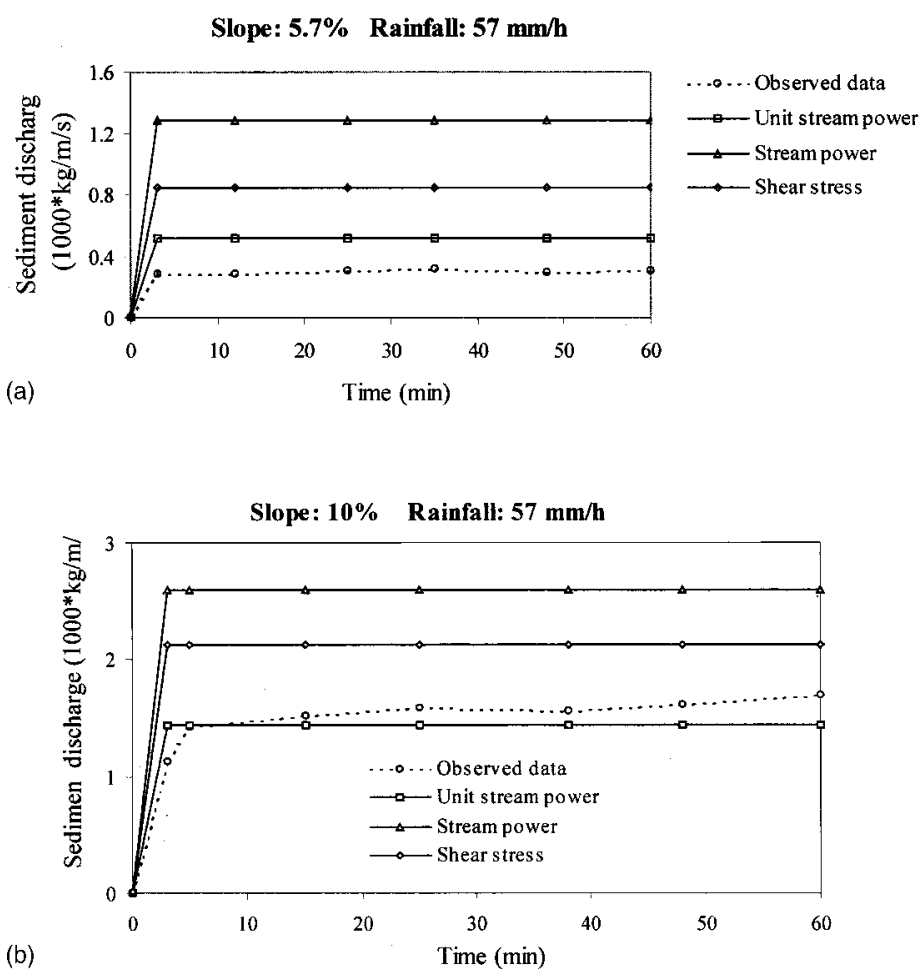

Slope: 15\% Rainfall: 57 mm/h
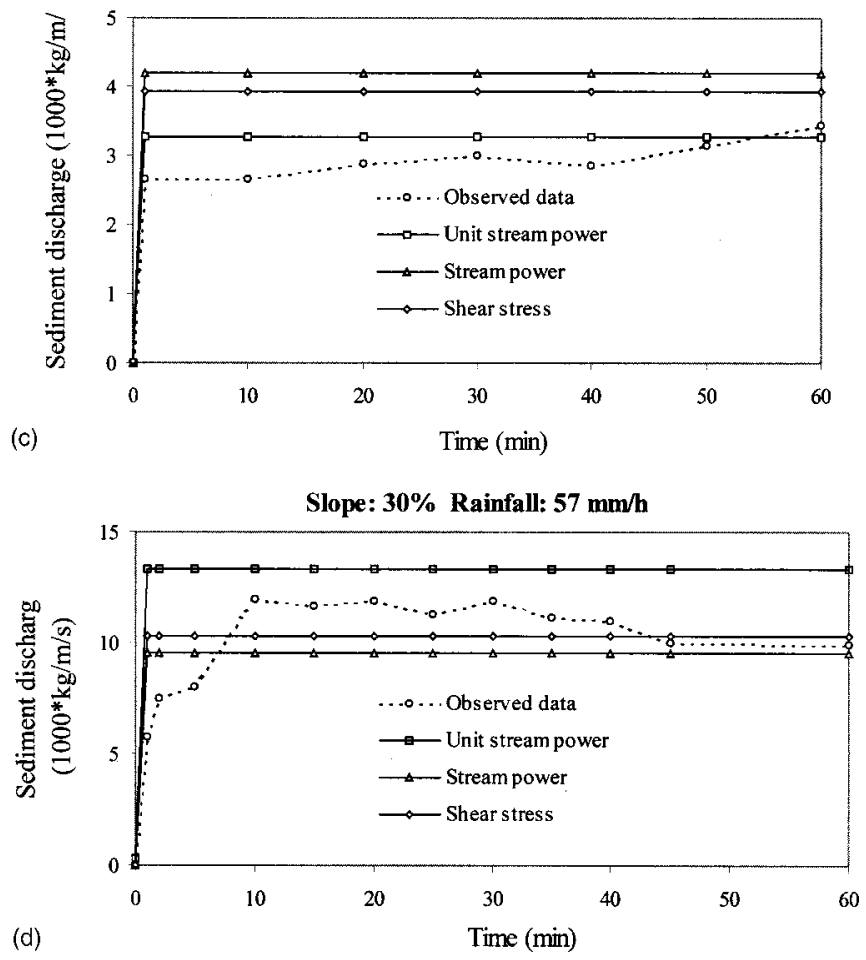

Slope: $40 \%$ Rainfall: $57 \mathrm{~mm} / \mathrm{h}$

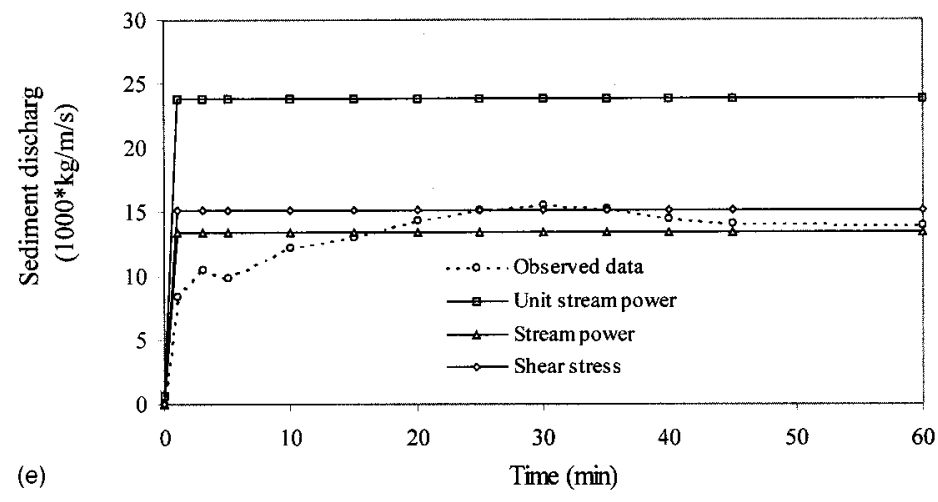

Fig. 2. (a) Simulation of observed data; $(S=5.7 \%, r=57 \mathrm{~mm} / \mathrm{h})$; (b) simulation of observed data; $(S=10 \%, r=57 \mathrm{~mm} / \mathrm{h}) ;(\mathrm{c})$ simulation of observed data; $(S=15 \%, r=57 \mathrm{~mm} / \mathrm{h})$; (d) simulation of observed data; $(S=30 \%, r=57 \mathrm{~mm} / \mathrm{h})$; and (e) simulation of observed data; $(S$ $=40 \%, r=57 \mathrm{~mm} / \mathrm{h}$ )

the simulations of observed sediment loads by the three models from 5.7, 10, 15, 30, and 40\% slopes, respectively, under 57 $\mathrm{mm} / \mathrm{h}$ rainfall intensity. Figs. 3(a-e) show the simulation of observed data by the three models from $5.7,10,15,30$, and $40 \%$ slopes, respectively, under $93 \mathrm{~mm} / \mathrm{h}$ rainfall intensity. Under 57 $\mathrm{mm} / \mathrm{h}$ rainfall intensity, the unit stream power model simulated the observed data from the $5.7,10$, and $15 \%$ slopes quite satisfactorily [Figs. $2(\mathrm{a}-\mathrm{c})$ ], though it overestimated the loads from steep slopes of 30 and $40 \%$ [Figs. 2(d and e)]. On the contrary, under $57 \mathrm{~mm} / \mathrm{h}$ rainfall intensity, the stream power and the shear stress models simulated the loads from the 30 and $40 \%$ slopes satisfactorily [Figs. 2(d and e)], while they overestimated the loads from the 5.7, 10, and 15\% slopes [Figs. 2(a-c)]. Under 93 $\mathrm{mm} / \mathrm{h}$ rainfall intensity, the unit stream power model simulated the loads from the $5.7 \%$ slope quite satisfactorily [Fig. 3(a)], though it underestimated the loads from the other slopes [Figs. $3(\mathrm{~b}-\mathrm{e})]$. On the other hand, under $93 \mathrm{~mm} / \mathrm{h}$ rainfall intensity, the shear stress and the stream power models simulated the loads from the 10 and $15 \%$ slopes satisfactorily [Figs. 3(b and c)], while they underestimated the loads from the 30 and $40 \%$ slopes [Figs. $3(\mathrm{~d}$ and $\mathrm{e})]$, and overestimated the loads from the $5.7 \%$ slope [Fig. 3(a)].

From the analysis of the model simulations of the observed data, it can be concluded that the unit stream power model performs better than the other two models in simulating nonsteady state erosion/sediment transport by sheet flow from bare slopes less than $10 \%$. The stream power and the shear stress models, on the other hand, perform better than the unit stream power model to simulate sediment loads from bare steep slopes greater than $20 \%$ under low rainfall intensity. The results also indicate that, in between the 10 and $20 \%$ slopes, under low rainfall intensities the unit stream power model gives better simulations; under high rainfall intensities the stream power and the shear stress models give better simulations. 

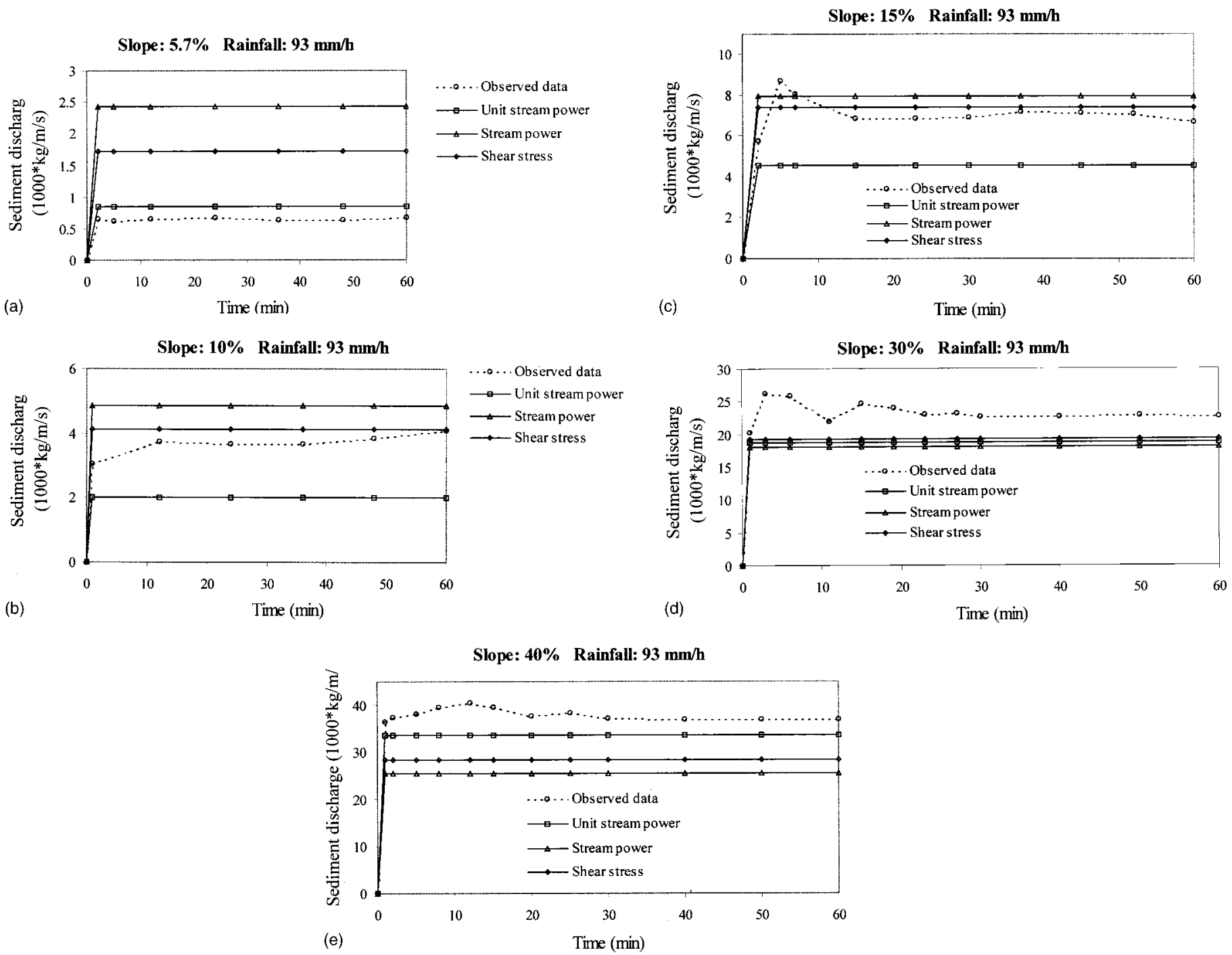

Fig. 3. (a) Simulation of observed data; $(S=5.7 \%, r=93 \mathrm{~mm} / \mathrm{h})$; (b) simulation of observed data; $(S=10 \%, r=93 \mathrm{~mm} / \mathrm{h})$; (c) simulation of observed data; $(S=15 \%, r=93 \mathrm{~mm} / \mathrm{h})$; (d) simulation of observed data; $(S=30 \%, r=93 \mathrm{~mm} / \mathrm{h})$; and (e) simulation of observed data; $(S$ $=40 \%, r=93 \mathrm{~mm} / \mathrm{h})$

\section{Concluding Remarks}

In this study, the unit stream power, stream power, and shear stress sediment transport capacity models, which had the basic form given by Eq. (1), were investigated to simulate nonsteady state sediment loads by sheet flow from steep bare slopes. For this purpose, the experimental data of Kilinc and Richardson (1973) were employed.

The models were calibrated by one of the data sets, and employed to simulate different sediment loads from different slopes $(5.7,10,15,30$, and $40 \%)$ under two different rainfall intensities (57 and $93 \mathrm{~mm} / \mathrm{h}$ ). The calibrated values of the model parameters were the same for each model, except for exponent $\left(k_{i}\right)$. The value of $\left(k_{i}\right)$ is given in between 1.0 and 2.5 in the literature. The model-calibration results in this study indicate that the value of $\left(k_{i}\right)$ is around 1.2 for the stream power model, 1.9 for the shear stress model, and 1.6 for the unit stream power model.

The models were found to be very sensitive to the changes in rainfall intensities and slopes. An increase/decrease in rainfall intensity and slope results in an increase/decrease in the sediment yield, and each model is able to capture this behavior. However, the performance of each model in simulating sediment yields from different slopes was found to be very much dependent upon the steepness of the slope, and the intensity of the rainfall. Therefore, the slope steepness and rainfall intensity play a major role in the selection of an appropriate sediment transport capacity model in simulating nonsteady state sediment loads by sheet flow.

The unit stream power model could be selected for simulating nonsteady state erosion/sediment transport from very mild bare hillslopes. Under low rainfall intensities, it could also be employed to simulate loads from mild/steep slopes. For the very steep slopes, the shear stress and stream power models could be employed. Under high rainfall intensities, the stream power and the shear stress models could also be employed to simulate loads from mild/steep slopes.

\section{Notation}

The following symbols are used in this paper:

$c=$ sediment concentration $\left(L^{3} / L^{3}\right)$;

$D=$ dominant variable; 


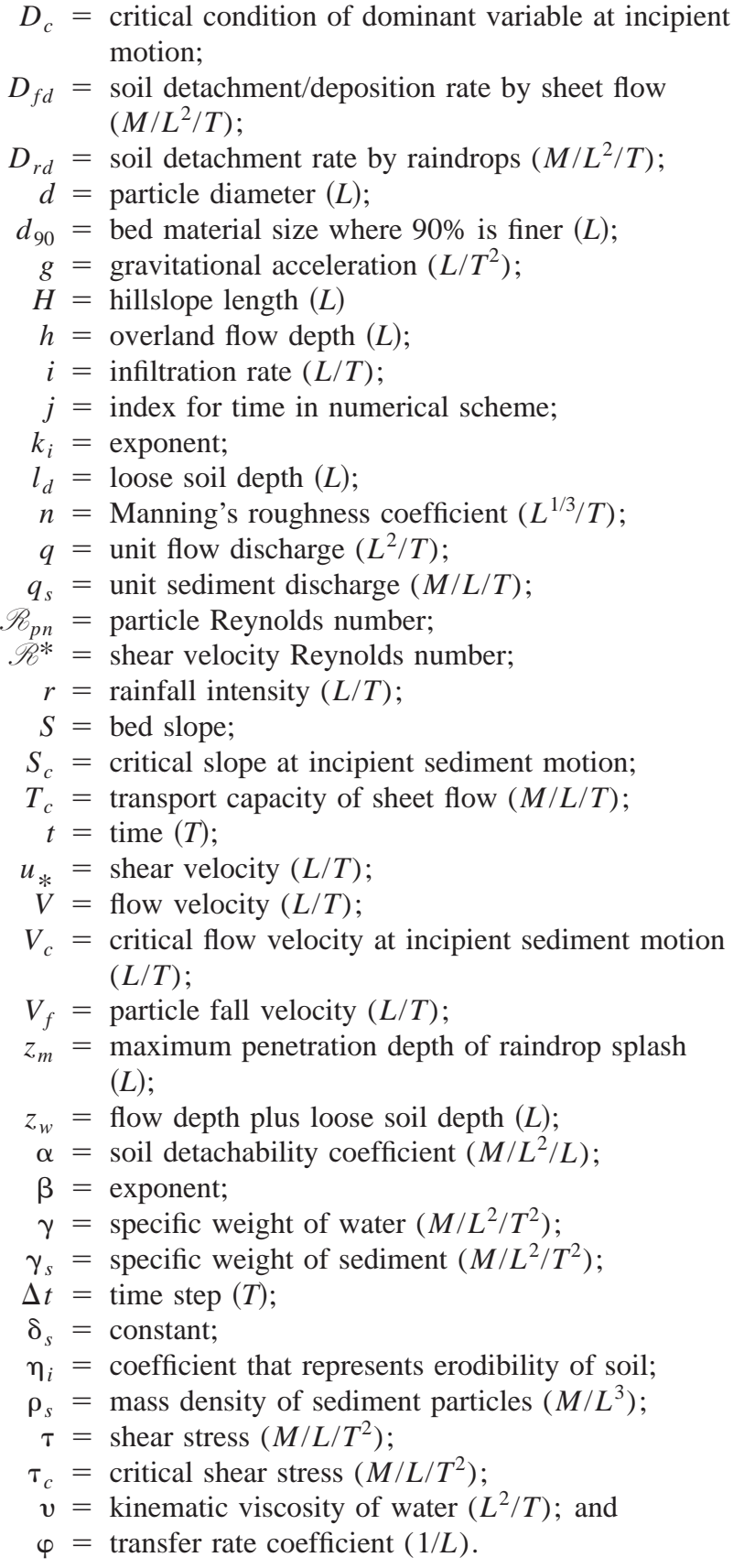

\section{References}

Alonso, C. V., Neibling, W. H., and Foster, G. R. (1981). "Estimating sediment transport capacity in watershed modelling." Transactions, American Society of Agricultural Engineers, St. Joseph, Mich., 24, 1211-1220.

Bagnold, R. A. (1960). "Sediment discharge and stream power." Preliminary Announcement, U.S. Geological Survey Circular 421, Menlo Park, Calif.

Flaxman, E. M. (1972). "Predicting sediment yield in western United States." J. Hydraul. Div., Am. Soc. Civ. Eng., 98(12), 2073-2085.

Foster, G. R. (1982). "Modelling the erosion process.” C. T. Haan et al., eds., American Society of Agricultural Engineers, St. Joseph, Mich., 295-380.

Foster, G. R., and Meyer, L. D. (1972). "A closed-form soil erosion equation for upland areas." Sedimentation: Symposium to Honor Professor H. A. Einstein, H. W. Shen, ed., Fort Collins, Colo., 12.1-12.9.

Foster, G. R., Meyer, L. D., and Onstad, C. A. (1977). "An equation derived from basic erosion principles." Transactions, American Soci- ety of Agricultural Engineers, St. Joseph, Mich., 20(4), 678-682.

Gessler, J. (1965). "The beginning of bedload movement of mixtures investigated as natural armouring in channels." Rep., Laboratory of Hydraulics and Water Resources, CIT.

Govindaraju, R. S., and Kavvas, M. L. (1991). "Modelling the erosion process over steep slopes: Approximate analytical solutions." J. Hydrol., 127, 279-305.

Govindaraju, R. S., Kavvas, M. L., Tayfur, G., and Krone, R. (1992). "Erosion control of decomposed granite at Buckhorn Summit." Final Project Rep., CALTRANS, Sacramento, Calif.

Guldal, V., and Muftuoglu, R. F. (2001). "2D unit sediment graph theory." J. Hydrologic Eng., 6(2), 132-140.

Kilinc, M., and Richardson, E. V. (1973). "Mechanics of soil erosion from overland flow generated by simulated rainfall." Hydrology Paper 63, Colorado State Univ., Fort Collins, Colo.

Leaf, C. (1974). "A model for predicting erosion and sediment yield from secondary forest road construction." Forest Service Research Note $R M-274$, Rocky Mountain Forest and Range Experiment Station, U.S. Dept. of Agriculture, Fort Collins, Co.

Li, R. M. (1979). "Water and sediment routing from watersheds." Modeling of rivers, H. W. Shen, ed., Wiley, New York, 9.1-9.88.

Loch, R. J. (1984). "Field rainfall simulator studies on two clay soils of the Darling Downs, Queensland, III. An evaluation of current methods of deriving soil erodibilities (K factors)." Austral. J. Soil Res., 22, 401-412.

Loch, R. J., and Donnollan, T. E. (1983a). "Field rainfall simulator studies on two clay soils of the Darling Downs, Queensland, I. The effect of plot length and tillage orientation on erosion processes and runoff rates." Austral. J. Soil Res., 21, 33-46.

Loch, R. J., and Donnollan, T. E. (1983b). "Field rainfall simulator studies on two clay soils of the Darling Downs, Queensland, II. Aggregate breakdown, sediment properties and soil erodibility." Austral. J. Soil Res., 21, 47-58.

McWhorter, D. B., et al. (1979). "Surface and subsurface water quality hydrology in surface mined watersheds." Rep. EPA-600/7-79-193a, U.S. Environmental Protection Agency, Cincinnati.

Megahan, W. F. (1974). "Erosion over time on several distributed granitic soils: A model." Paper INT-156, Intermountain Forest and Range Experiment Station, U.S. Dept. of Agriculture, Ogden, Utah.

Meyer, L. D. (1971). "Soil erosion by water on upland areas." River mechanics, Vol. II, H. W. Shen, ed., Fort Collins, Colo.

Meyer, L. D., and Wischmeier, W. H. (1969). "Mathematical simulation of the process of soil erosion by water." Transactions, American Society of Agricultural Engineers, St. Joseph, Mich., 12(6), 754-762.

Meyer-Peter, E., and Muller, R. (1948). "Formula for bed load transport." 2nd Meeting, Int. Association for Hydraulic Structures.

Moore, I. D., and Burch, G. J. (1986). "Sediment transport capacity of sheet and rill flow: Application of unit stream power theory." Water Resour. Res., 22(8), 1350-1360.

Mosley, M. P. (1972). "An experimental study of rill erosion.” MS thesis, Colorado State Univ., Fort Collins, Colo.

Moss, A. J. (1979). "Thin-flow transportation of solids in arid and nonarid areas: A comparison of processes." IAHS-AISH Publication, Wallingford, U.K., 128, 435-445.

Moss, A. J., Green, P., and Hutka, J. (1982). "Small channels: Their experimental formation, nature and significance." Earth Surf. Processes Landforms, 7, 401-415.

Moss, A. J., and Walker, P. H. (1978). "Particle transport by continental water flows in relation to erosion, deposition, soils, and human activities." Sediment Geol., 20, 81-139.

Moss, A. J., Walker, P. H., and Hutka, J. (1980). "Movement of loose, sandy detritus by shallow water flows: An experimental study." Sediment Geol., 25, 43-66.

Mutchler, C. K., and Young, R. A. (1975). "Soil detachment by raindrops." Proc., Sediment-Yield Workshops, ARS-S-40, U.S. Dept. of Agriculture, Oxford, Miss., 113-117.

Partheniades, E. (1972). "Results of recent investigation on erosion and deposition of cohesive sediments." Sedimentation: Symposium to 
Honor Professor H. A. Einstein, H. W. Shen, ed., Fort Collins, Colo., 20.1-20.29.

Rose, C. W., Williams, J. R., Sander, G. C., and Barry, D. A. (1983a). “A mathematical model of solid erosion and deposition processes, I. Theory for a plane land element." Soil Sci. Soc. Am. J., 47(5), 991995.

Rose, C. W., Williams, J. R., Sander, G. C., and Barry, D. A. (1983b). “A mathematical model of solid erosion and deposition processes, II. Application to data from an arid zone catchment." Soil Sci. Soc. Am. J., 47(5), 996-1000.

Rouse, H. (1938). Fluid mechanics for hydraulic engineers, Dover, New York.

Rowlinson, D. L., and Martin, G. L. (1971). "Rational model describing slope erosion." J. Irrig. Drainage Div., 97(1), 39-50.

Sharma, P. P., Gupta, S. C., and Foster, G. R. (1993). "Predicting soil detachment by raindrops." Soil Sci. Soc. Am. J., 57, 674-680.

Smith, R. E. (1976). "Simulation erosion dynamics with a deterministic distributed watershed model." Proc., 3rd Federal Interagency Sedimentation Conf., Vol. 1, Water Resources Council, Washington, D.C., $163-173$.

Tayfur, G. (1990). "Modeling of two dimensional overland flows." MS thesis, Univ. of California, Davis, Calif.

Tayfur, G. (2001). "Modeling two dimensional erosion process over infiltrating surfaces." J. Hydrologic Eng., 6(3), 259-262.
Wilson, B. N., Barfield, B. J., and Moore, I. D. (1982). "A hydrology and sedimentology watershed model." Spatial Publication, Dept. of Agricultural Engineering, Univ. of Kentucky, Lexington, Ky.

Wilson, B. N., Barfield, B. J., Moore, I. D., and Warner, R. C. (1984). “A hydrology and sedimentology watershed model, II. Sedimentology component." Transactions, American Society of Agricultural Engineers, St. Joseph, Mich., 27(5), 1378-1384.

Woolhiser, D. A. (1974). "Unsteady free-surface flow problems." Proc., Institute on Unsteady Flow in Open Channels, Colorado State Univ., Fort Collins, Colo., 195-213.

Woolhiser, D. A., Smith, R. E., and Goodrich, D. C. (1990). "KINEROS-A kinematic runoff and erosion model: Documentation and user manual." ASR-77, U.S. Dept. of Agriculture, Agriculture Research Service.

Yang, C. T. (1972). "Unit stream power and sediment transport." J. Hydraul. Div., Am. Soc. Civ. Eng., 98(10), 1805-1826.

Yang, C. T. (1973). "Incipient motion and sediment transport." J. Hydraul. Div., Am. Soc. Civ. Eng., 99(10), 1679-1704.

Yang, C. T. (1996). Sediment transport theory and practice, McGrawHill, New York.

Yang, C. T., and Song, C. C. S. (1979). "Theory of minimum rate of energy dissipation." J. Hydraul. Div., Am. Soc. Civ. Eng., 105(7), 769-784. 